DOI: $10.33947 / 1980-6469-v 14 n 2-3309$

\title{
EDUCAÇÃO E A PRÁTICA DOCENTE NO MUNDO HODIERNO
}

\section{EDUCATION AND TEACHING PRACTICE IN THE HODERNERN WORLD}

\author{
Nivaldo Nogueira de Ávila¹, Michel Canuto de Sena², Fernando Moreira Freitas da Silva ${ }^{3}$, \\ Paulo Roberto Haidamus de Oliveira Bastos ${ }^{4}$, Alcione Maria dos Santos ${ }^{5}$
}

\section{RESUMO}

O presente estudo aponta e discute aspectos da metodologia de ensino docente na atualidade. Dentre os principais tópicos, podemos citar a formação de professores com embasamento na teoria do capital humano, o que acaba por interferir diretamente na organização do sistema educacional. A presente pesquisa utilizou a revisão narrativa e compreensiva de estudos e pesquisas sobre a educação e a prática docente no mundo hodierno. $O$ atual sistema educacional evidencia o desenvolvimento da formação docente por meio de novas tecnologias e entende que a identidade profissional também incorpora o espaço conquistado para desenvolver seu trabalho de forma institucionalizada. Assim, a utilização da educação como ferramenta das classes dominantes investiga pressupostos que embasam a formação e prática do professor, apontando as principais dificuldades encontradas para o desenvolvimento da prática. Frente ao exposto, os dados demonstram a evolução da educação e também as práticas educacionais aplicadas. Destarte, devem ser construídos alicerces que possam sustentar o conhecimento pedagógico especializado.

PALAVRAS-CHAVE: Educação; teoria do capital humano; prática docente; professor.

\section{ABSTRACT}

The present study points out the aspects of teaching approaches and methodologies in the present time. Among the main topics, we can mention the formation of teachers based on human capital theory, which directly interferes in the organization of the educational system. Our educational system evidences the development of the teacher training through new technologies and understands that the professional identity also incorporates the space conquered to develop its work in an institutionalized way. Thus, the use of education as a tool of the dominant classes investigates assumptions that support the formation and practice of the teacher, pointing out the main difficulties encountered for the development of the practice. Given the above, the data demonstrate the evolution of education and also the educational practices applied. Thus, the foundations must be built that can support the specialized pedagogical knowledge.

KEYWORDS: Education; human capital theory; teaching practice; teacher.

1 Graduado em Pedagogia pela Universidade Federal da Grande Dourados (2000), Bacharel em Teologia pela Faculdade Teológica Batista Ana Wollerman (Dourados/MS), Pós-Graduação em Mídias na Educação pela Universidade Federal de Mato Grosso do Sul (Campus de Campo Grande/MS) e atualmente Cursando Mestrado em Educação Social pela UFMS - Campus do Pantanal.

2 Doutorando e Mestre pelo Programa de Pós-Graduação em Saúde e Desenvolvimento da Região Centro-Oeste da Universidade Federal de Mato Grosso do Sul (UFMS). Atua como professor de Bioética e Direito Civil.

3 Doutorando em Direito do Estado (USP) e Mestre em Direito Negocial (UEL). Atua como Juiz de Direito e Professor da Escola da Magistratura de Mato Grosso do Sul.

4 Professor Doutor do Programa de Pós-Graduação em Saúde e Desenvolvimento da Região Centro-Oeste da Universidade Federal de Mato Grosso do Sul. Atualmente é membro do Comitê de Ética (UFMS).

5 Docente na Universidade Federal de Mato Grosso do Sul (UFMS), na Faculdade de Artes, Letras e Comunicação (FAALC). Atuação na área de Letras, com ênfase em Literatura Brasileira/Literatura e Ensino. Líder do Grupo de Estudo e Pesquisa em Literatura e Educação (GEPELE). Doutorado (2007) e Mestrado (2003) em Estudos Literários, pelo Programa de PósGraduação em Letras da Universidade Estadual Paulista (UNESP/Araraquara). Graduação em Letras - habilitação em Língua Portuguesa e Língua Alemã - pela Universidade Estadual Paulista (UNESP/Araraquara). 


\section{INTRODUÇÃO}

O presente estudo faz reflexão sobre a educação e a prática docente no mundo moderno, em que conceitos sociais, afetivos e tecnológicos se cruzam, abrindo caminhos para nova metodologia de ensino. Nesse contexto, a educação é vista como meio de transformação. Para tanto, a pesquisa utilizou da metodologia da revisão narrativa com recortes analíticos de artigos científicos, livros e demais mecanismos de pesquisa.

Nesse processo, o mundo hodierno se revela como expressão da vivência em tempos de mudanças, contestações, crise dos conhecimentos e da sociedade interconectada. Em consequência disso, buscam-se novas práticas que aproximam da condição humana, em que a atualidade cede lugar à pluralidade cultural, étnica, política e científica, tendo em vista que a escola não pode estar desvinculada da vida e do mundo que a rodeia.

Desse modo, o tema educação tornou-se recorrente nos discursos políticos, passando a ser utilizada como instrumento de manutenção do status quo, servindo-se da educação para propagar a ideologia da classe dominante, reforçando a manutenção da sociedade de classes.

Nesse diapasão, a teoria do capital humano deriva do neoliberalismo, e está baseada na crise do modelo taylorista-fordista, associada à redefinição das relações de trabalho e do papel do sistema educacional. Assim, nota-se o discurso de que a eficácia da educação é o instrumento de desenvolvimento econômico, distribuição de renda e equalização social, atribuindo ao indivíduo a culpa pelo fracasso ou insucesso.

Dessa forma, para chegar a um entendimento é preciso observar as dúvidas, dilemas e incertezas que os professores enfrentam. Estudos que analisam discursos dos professores se tornam parte do processo transformador que ocorre dentro ou fora da sala de aula.

Posto isso, o presente estudo se desenvolve por meio de análises da educação como mudança social, dando ênfase sobre a educação no mundo hodierno e a teoria do capital humano, logo após analisa a identidade profissional do professor.

\section{METODOLOGIA}

A presente pesquisa utilizou a revisão narrativa e compreensiva de estudos e pesquisas sobre a educação e a prática docente no mundo hodierno. As referências apresentadas pela literatura foram coletadas a partir das bases de dados Medline, SciELO e Lilacs.

A busca se limitou aos estudos de corte transversal, publicados no período compreendido entre 2012 e 2018, nos idiomas português, inglês e espanhol. Foram analisados, ainda, estudos que investigam as ações necessárias para a educação e a prática docente no mundo atual.

Desse modo, a escolha da temática baseou-se na importância que a educação apresenta na atualidade, buscando assim, mecanismos que possam potencializar e desenvolver novos pensamentos e práticas escolares com maior eficácia.

Assim, a revisão narrativa, também conhecida como tradicional, apresenta uma discussão aberta, pois não exige um protocolo rígido para ser confeccionada. A busca das fontes não é pré-definida e a seleção de artigos é arbitrária. Desse modo, cabe ao autor realizar o viés de seleção com interferência da percepção subjetiva.

Os descritores utilizados na busca da revisão foram: educação; teoria do capital humano; prática docente; professor, nos idiomas português e inglês. Como resultado dessa estratégia de busca, encontrouse um total de 3.250 artigos nas bases selecionadas.

\section{REVISÃO BIBLIOGRÁFICA}

\subsection{EDUCAÇÃO COMO MUDANÇA SOCIAL}

O aprendizado pode ser considerado como atividade intencional e estruturada do docente, para obtenção de determinados objetivos pedagógicos, tendo em vista que a educação busca melhorar as relações humanas no contexto em que vivem, por via da participação social, de diretrizes legais, formando cidadãos que exercitem o pensamento crítico e se tornem sujeitos ativos com poder de transformação de sua realidade (JANUÁRIO, 1996).

Tendo em vista que a educação é um meio pelo qual os indivíduos podem crescer potencializando e 
adquirindo consciência, ela deve estar voltada para aperfeiçoar e promover as capacidades humanas (JANUÁRIO, 1996).

Nesse sentido, o processo de formação docente subdivide-se em quatro fases: (I) o pré-treino integra experiências vivenciadas pelos indivíduos enquanto alunos; (II) formação inicial, conhecimentos pedagógicos e didáticos; (III) fase da iniciação, formas de aprendizagem na prática educacional; (IV) e formação permanente, que retrata o aperfeiçoamento profissional constante (BARROS, 2012).

A educação transformadora tem como papel a socialização, estimulando mudanças nas relações sociais e acadêmicas e no processo produtivo de qualificação humana. Nesse aspecto, o sistema educacional da sociedade é responsável pela produção e reprodução da estrutura de valores, pelos os quais os indivíduos definem seus objetivos e fins específicos (FRIGOTTO, 1996).

Assim, a política educacional, parte da totalidade e passa a ser articulada com planejamento dentro da sociedade, tendo em vista que ela não possui mecanismo de ajustamento do indivíduo. A teoria de Dewey se baseia no pensamento liberal, centrada na experiência do indivíduo:

Quando a criança inicia sua escolaridade, leva em si quatro "impulsos inatos - o de comunicar, o de construir, o de indagar e o de expressarse de forma mais precisa" - que constituem "os recursos naturais, o capital para investir, de cujo exercício depende o crescimento ativo da criança". A criança também leva consigo interesses e atividades de seu lar e do entorno em que vive, cabendo ao educador a tarefa de usar a "matéria-prima", orientando as atividades para "resultados positivos" (DEWEY, 2010, p.15).

Conforme os ensinamentos de Dewey (2010), o pensamento teórico da educação está centrado na capacidade de raciocínio e no espírito crítico do aluno, e a prática docente baseia-se na liberdade que o aluno possui para elaborar as próprias certezas, conhecimentos e regras morais. Isso significa que o educador precisa estar atento às condições e aos meios que modelam o aprendizado do aluno (PEREIRA et al., 2009).
Desse modo, no século XX, a educação tornouse permanente e social, passando a difundir novas ideias de que não existia faixa etária para a busca de conhecimento, pois o conhecimento se estende pela vida e não é neutro (GADOTTI, 2000). Todavia três tendências se convergem para tornar a escola conservadora e convencional:

Inércia do próprio sistema, a tendência natural do formalismo a perpetuar-se dentro de si mesmo, por toda parte; segundo, a influência de sinais exteriores de aprendizado, a importância dada a esses sinais, o que tornou, afinal, a matéria meramente convencional; e, terceiro, a possibilidade que os "conservadores" geralmente obtêm, de usar a escola para fixar, na mocidade, opiniões e atitudes que julgam de necessidade manter, de qualquer forma. [...] Até há pouco tempo, a própria escola, resistindo à mudança, foi, em geral, um baluarte contra a mudança social (GHANEM, 2012, p. 220, apud KILPATRICK, 1964, p. 43).

Com a globalização, surge uma nova etapa no desenvolvimento humano advinda dos avanços tecnológicos que encurtaram os espaços com ferramentas na mídia eletrônica e na capacidade de impor determinados valores ou verdades do sistema dominante. Nesse contexto, a educação passa a ser controlada pela globalização, como instrumento na cultura, no modo de pensar e agir (GHANEM, 2012).

Os sistemas educacionais ainda não atingiram patamares de avaliações suficientemente com base no impacto da comunicação audiovisual e da informática, sendo utilizados recursos tradicionais que nem sempre são eficazes para crianças e adolescentes. Assim, os defensores da informatização da educação sustentam a necessidade de mudança nos métodos de ensino, resguardando a capacidade de pensar em vez de desenvolver a memória, atribuindo nova função à escola, a de ensinar a pensar criticamente (GADOTTI, 2000).

Para isso, é preciso dominar mais metodologias e linguagens eletrônicas, tendo em vista que as redes sociais têm poder de eliminar hierarquias e possivelmente estimular o pensamento crítico, aproximando as pessoas. 
Nesse contexto, a educação torna-se uma chave para mudança social e por meio dela o indivíduo se torna crítico, compartilha conhecimentos e se desenvolve de forma econômica, social e cultural, podendo, ainda, reduzir a incidência de pobreza, protegendo o meio ambiente e minimizando a violência (GADOTTI, 2000).

Partindo desse pressuposto, educar é fundamental para construir uma sociedade democrática em suas dimensões sociais, éticas e políticas. Cada vez mais a educação tem maior relevância no processo de mudança social. A responsabilidade social da escola e dos profissionais se desenvolve por meio do relacionamento interpessoal entre a escola, os professores e a comunidade, buscando formas para fortalecer o ambiente educacional como unidade. Assim, consequentemente, promove-se mudança no sentido de reconstruir uma sociedade mais justa e igualitária (PORTO, 2017).

A educação busca alcançar a promoção de mudanças sociais, preservar os princípios da igualdade e fraternidade, além de traçar caminhos para a construção da liberdade e da justiça entre os homens. Mas, para que se faça cumprir a função da escola, é preciso que, além do desenvolvimento da aprendizagem cognitiva, o homem também aprenda sobre solidariedade (PORTO, 2017).

[...] a educação nova, obra de cooperação social, deveria atrair, solicitar e congregar para um fim comum todas as forças e instituições sociais, a escola e a família, pais e professores que antes operavam, sem compreensão recíproca, em sentidos divergentes, senão oposto (AZEVEDO, 2010, p. 52).

Logo, o ensino como processo original difere, e muito, do ensino atual, pois a educação é influenciada pela época, lugar e filosofia defendida pela sociedade em constante mudança e evolução.

\subsection{A educação no mundo hodierno e a teoria do capital humano}

O mundo atual tem se revelado com mudanças em conhecimentos na sociedade interconectada, que busca sentidos originais e novas práticas próximas da condição humana, cedendo lugar à pluralidade cultural, étnica, política e científica. Desse modo, a escola não pode se desvincular das pessoas e dos fatores externos, mas deve estar em sintonia com a comunidade, pois cabe à mesma transmitir conhecimento. Assim, cabe fazer relações entre dados, informações e ideias (SANTOS et al., 2010).

Nesse diapasão, a dimensão da informação no mundo global do conhecimento, a diversificação de produtos e processos fizeram crescer a capacidade de processar informações (ENGUITA, 2004). Tornou a educação no mundo hodierno organizada, planejada e com insumos para satisfazer e corresponder às necessidades demandadas pelo mercado, preparando mão de obra qualificada para atender os meios de produção que buscam acumular capital.

Nesse contexto, para a teoria do capital humano, a educação serve aos interesses do capital, preparando o sujeito para exercer o seu papel na sociedade e satisfazer a necessidade da formação de mão de obra para o mercado de trabalho. A teoria do capital humano gera discussão acerca da eficácia da educação como instrumento de desenvolvimento econômico, distribuição de renda e equalização social. Assim,

A teoria do Capital Humano enquanto teoria do desenvolvimento --concebe a educação como produtora de capacidade de trabalho, potenciadora de trabalho e, por extensão, potenciadora da renda, um capital (social e individual), um fator do desenvolvimento econômico e social. Quanto ao segundo sentido, ligado ao primeiro - teoria da educação - a ação pedagógica, a prática educativa escolar reduzem-se a uma questão técnica, a uma tecnologia educacional cuja função precípua é ajustar requisitos educacionais a pré-requisitos de uma ocupação no mercado de trabalho de uma dada sociedade. Trata-se da perspectiva instrumentalista e funcional de educação (FRIGOTTO, 2003, p.17).

Com relação à ideia apresentada, a teoria do capital humano trata das desigualdades, apresenta-se útil para ofuscar a realidade e manter a consciência do sujeito alienada. Em suas concepções gerais, favorece 
a análise sobre o papel da educação dentro da perspectiva de interesses neoliberais e traz implicações às práticas educativas (CABRAL; SILVA; SILVA, 2016).

A formação dos profissionais da educação por meio de diversos mecanismos ocorre pela transmissão de conhecimentos esvaziados de criticidade, organizada e sistematizada com objetivo de preparar indivíduos para atuarem no sistema de produção (KUENZER, 1997). Nesse contexto, a escola se torna funcional ao capitalismo, devido à sua ineficiência e à ação unilateral com:

[...] Improdutividade, dentro das relações capitalistas de produção, torna-se produtiva na medida em que a escola é desqualificada para a classe dominada, para os filhos dos trabalhadores, ela cumpre, ao mesmo tempo, uma dupla função na reprodução das relações capitalistas de produção: justifica a situação de explorados e, ao impedir o acesso ao saber elaborado, limita a classe trabalhadora na sua luta contra o capital (FRIGOTTO, 1993, p. 224).

A teoria do capital humano vincula a educação, desenvolvimento, distribuição de renda. Configurada como teoria do desenvolvimento, não se desvia da função de defesa das relações sociais de produção. Esse supositício afirma que a educação surge com caráter messiânico e visa a solução para os problemas sociais. Assim, o papel da escola é de produzir posturas e valores direcionados para a prática mediadora que satisfaz interesses do capital (KUENZER, 1997). Desse modo,

[...] a relevância dos vínculos que a teoria do capital humano busca estabelecer entre educação e desenvolvimento, educação e trabalho, vale ser explorada não pelo poder que tem de explicar, mas, ao contrário, pelo poder de mascarar a verdadeira natureza desses vínculos no interior das relações sociais de produção da sociedade capitalista. Ao pautar-se por um método positivista de análise, concebendo as relações sociais da sociedade do capital como dadas, produtos naturais, ou simplesmente com relações técnicas, a teoria do capital humano acaba por se constituir numa análise a-histórica. $\mathrm{O}$ caráter circular das análises decorre de sua função de efetivar uma apologia das relações sociais de produção da sociedade capitalista (FRIGOTTO, 2003, p.20).

Sob essa ótica, para Gramsci (1979), a educação deveria promover a elevação cultural das massas, sendo que os principais agentes dessas mudanças seriam os intelectuais, limitando-se a escola a ser um dos instrumentos para este fim. Entretanto, essa escola reproduziria o status quo, ou seja, a sociedade dividida em classes e ideologias, com fracasso escolar ou insucesso pessoal do indivíduo.

Segundo Marx, a função social da educação é combater a alienação e a desumanização, desmascarando as relações sociais de dominação e exploração estabelecidas pelo capitalismo, tornando cada indivíduo consciente da realidade social em que está inserido e apto a defender o fim das desigualdades sociais, transformando a sociedade (MARX, 1986).

Nesse sentido, para Marx e Engels, a educação na sociedade capitalista se tornou um elemento de manutenção e perpetuação da hierarquia social. Pelo mesmo viés, Gramsci denominou a educação como um instrumento da hegemonia ideológica burguesa.

\subsection{A identidade profissional e o papel do professor}

No contexto educacional, a identidade docente possui simetria social e particular, com espaço conquistado pelo professor para desenvolver seu trabalho, de forma institucionalizada, com base na identidade coletiva e padronizado, resultando das experiências interpessoais, contexto social, cultural e institucional do seu quotidiano (GOMES et al., 2013).

Desse modo, a formação do professor consiste em processo de socialização, podendo inferir nas interações sociais como elementos que contribuem para a construção da sua identidade. Além da prática profissional, surge o desenvolvimento dessa identidade profissional (GOMES et al., 2013).

O trabalho pedagógico possui papel fundamental para promover a educação libertadora e emancipatória, pautada pela criticidade. Portanto, faz-se necessário um processo pedagógico definido e voltado aos interesses da classe trabalhadora. 
Nos processos de formação de professores, é preciso considerar a importância dos saberes das áreas de conhecimento (ninguém ensina o que não sabe), dos saberes pedagógicos (pois o ensinar é uma prática educativa que tem diferentes e diversas direções de sentido na formação do humano), dos saberes didáticos (que tratam da articulação da teoria da educação e da teoria de ensino para ensinar nas situações contextualizadas), dos saberes da experiência do sujeito professor (que dizem do modo como nos apropriamos do ser professor em nossa vida). Esses saberes se dirigem às situações de ensinar e com elas dialogam, revendo-se, redirecionando-se, ampliando-se e criando (PIMENTA, 2005, p. 71).

Desse modo, o trabalho docente precisa estar voltado para promoção do desenvolvimento social, político e econômico e buscar novos conhecimentos, para manter ideias inovadoras e aprendizados atualizados, acompanhando as constantes transformações no mundo e, nesse aspecto, haverá algo novo para aprender.

[...] produzir direta e intencionalmente, em cada indivíduo singular, a humanidade que é produzida histórica e coletivamente pelo conjunto dos homens Assim, o objeto da educação diz respeito, de um lado, à identificação dos elementos culturais que precisam ser assimilados pelos indivíduos da espécie humana para que eles se tornem humanos e, de outro lado e concomitantemente, à descoberta das formas mais adequadas para atingir esse objetivo (SAVIANI, 2005, p.13).
Nos processos de formação, as reflexões são essenciais para pensar sobre mudanças nos modos de organização curricular e do ensino dos cursos de formação de professores, evitando-se a vetusta postura somente de se formar sem qualquer comprometimento prospectivo (DIAS; SOUZA, 2017).

Nesse sentido, o professor deve afastar de suas crenças e costumes, devendo ser capaz de fazer uma adequada análise crítica de sua realidade e, desse modo, proporcionar aos alunos o devido conhecimento para que estes alcancem a própria compreensão social.

\section{CONSIDERAÇÕES FINAIS}

Nesse contexto, a identidade do professor é construída por meio dos espaços sociais, trabalhando com realidades e públicos diferentes, objetivando estabelecer relações entre as pessoas pela via da socialização dos saberes e da forma como cada professor interpreta, organiza e trabalha.

Os conhecimentos permitem a construção de práticas concretas, por meio de mudanças nas condições de trabalho, demandas sociais e inovações tecnológicas. Além do mais, devem constituir-se em alicerces que sustentam a construção do conhecimento pedagógico especializado.

Em síntese, no cenário escolar o desafio do professor é continuo e as conquistas são advindas no dia a dia em cada atividade aplicada, buscando melhorar a formação do ser humano, tendo em vista que o mundo moderno e suas tecnologias influenciam a formação e a criação da personalidade dos seres humanos. 


\section{REFERÊNCIAS}

AZEVEDO, F. Educação, Brasil e história: fundação Joaquim Nabuco. Coleção Educadores MEC. Recife: Editora Massangana, 2010.

BARROS, M. M. P. Prática de ensino supervisionada em ensino da educação visual e tecnológica no ensino básico. Relatório Final de Estágio Profissional apresentado à Escola Superior de Educação de Bragança para a obtenção do Grau de Mestre em Ensino da Educação Visual e Tecnológica no Ensino Básico, 2012. Disponível em: <http://scienceresearch.com/ scienceresearch/link.htm>. Acesso em: 12 abr. 2018.

CABRAL, A.; SILVA, C. L. M.; SILVA, L. F. L. Teoria do capital humano, educação, desenvolvimento econômico e suas implicações na formação de professores. Revista Principia, n. 32, dez. 2016, p. 35-41.

DEWEY, J.; WESTBROOK, R. B.; TEIXEIRA, A. Educação - Pensadores - História. Coleção Educadores MEC. Recife: Fundação Joaquim Nabuco, Editora Massangana, 2010.

DIAS, M. S. SOUZA, N. M. M. Contribuições para compreender a formação na licenciatura e na docência. Educação em Revista, Belo Horizonte, n. 33, p. 1-24, 2017. Disponivel em: http://www.scielo.br/pdf/edur/v33/19826621-edur-33-e157758.pdf. Acesso em: 16 abr. 2018.

ENGUITA, M. F. A educação e a mudança social. In: ENGUITA, M. F. Educar em tempos incertos. Porto Alegre: Artmed, 2004.

FRIGOTTO, G. Educação, crise do trabalho assalariado e do desenvolvimento: teorias em conflito. In: Educação e Crise do Trabalho: perspectivas de final de século. Petrópolis, RJ: Vozes, 1998.

FRIGOTTO, G. Educação e a crise do capitalismo real. São Paulo: Cortez, 2003.

GHANEM, E. A educação na mudança social: lugar central, lugar secundário e o lugar nenhum. Educar em Revista, Curitiba, Brasil, n. 45, p. 213-229, jul./set. 2012.
A produtividade da escola improdutiva: um (re) exame das relações entre educação e estrutura econômica social capitalista. São Paulo: Cortez, 1984.

GRAMSCI, A. Os intelectuais e a organização da cultura. Rio de Janeiro: Civilização Brasileira, 1979.

GADOTTI, M. Perspectivas atuais da educação. Revista São Paulo em perspectiva, v. 14, n. 2, 2000.

GOMES, P. M. S.; FERREIRA, C. P.; PEREIRA, A. L.; BATISTA, P. M. F. A identidade profissional do professor: um estudo de revisão sistemática. Revista Brasileira de Educação Física Esporte, v.47, n.2, p. 247267, abr./jun. 2013.

JANUÁRIO, C. Do pensamento do professor à sala de aula. Coimbra: Livraria Almedina, 1996.

KUENZER, A. Z. Ensino médio e profissional: as políticas do Estado neoliberal. São Paulo: Cortez, 1997.

MARX, K; ENGELS, F. A ideologia alemã. São Paulo: Ciências Humanas, 1986.

PEREIRA, E. A; MARTINS, J. R.; ALVES, V. dos S. e DELGADO, E. I. A contribuição de John Dewey para a educação. Revista Eletrônica de Educação. São Carlos, SP: UFSCar, v. 3, n. 1, p. 154-161, maio 2009.

PIMENTA, S. G. Docência no ensino superior. 2. ed. São Paulo: Cortez, 2005.

PORTO, V. S. P. A educação tem uma função de mudança social. 2017: Disponível em: https://www.webartigos.com/storage/app/uploads/public/592/456/88d/ 59245688d610c571489749.pdf. Acesso em: 14 abr. 2018.

SANTOS, S. C.; PERIPOLLI, A.; OLIVEIRA, M. P.; FREITAS, S. N. Avaliação no mundo hodierno: um intervir sobre a produção do conhecimento. Revista lbero-americana de Educb ação, n. 53, v. 1, jun. 2010.

SAVIANI, D. Pedagogia histórico-crítica: primeiras aproximações. Rio de Janeiro: Fiocruz, 1987. 